The Social Sciences 5 (6): 538-544, 2010

ISSN: $1818-5800$

(C) Medwell Journals, 2010

\title{
Developing a Model of Learning Organization at a Technical College
}

\author{
${ }^{1}$ Chuthaphon Bunwan, ${ }^{2}$ Kowat Tesputa and ${ }^{3}$ Prasit Nimchinda \\ ${ }^{1}$ Graduate School, Mahasarakham University, Kantarawichai District, \\ 44150 Mahasarakham, Thailand \\ ${ }^{2}$ Department of Educational Research and Development, \\ ${ }^{3}$ Department of Educational Administration, Faculty of Education, \\ Mahasarakham University, Muang District, 44000 Mahasarakham, Thailand
}

\begin{abstract}
From an analysis of the organizational contexts to find out strategies for developing government officials and personnel of vocational education, it has been found that knowledge management in educational institution offices has not yet been systematic; there are limited access channels to the body of knowledge and organizations lack good learning and good governance. The purposes of this study were to develop a model of learning organization at a technical college and to examine outcomes of implementing the model of learning organization at Suwannaphum Technical college using the mixed methodology research. The research stages consisted of drafting the model of learning organization at the Technical College having the obtained model checked by experts and having the model tried out at Suwannaphum Technical College. The instruments used for collecting data were a questionnaire for checking the model, a note-taking form on academic seminar outcomes, a note-taking form on brainstorming outcomes, an evaluation form on coverage of learning organization plans, an evaluation form on teacher's teaching and an evaluation form on the project. The statistics used for analyzing the collected data were mean ( $\boldsymbol{x})$ and Standard Deviation (SD). The study findings revealed that the model of being organization learning at the technical college consisted of these factors: structure, vision, mission, context and culture, instructional leadership, communication, knowledge management and transference, technology and information, team learning, encouragement and motivation, personnel development and evaluation. For the outcomes of trying out the model of being learning organization at Suwannaphum Technical college by means of seminar at the organization level, it was found that 15 underlying projects were obtained and for developing learning organization plans at the department level for evaluating the projects their opinions were at a high level. The model tryout through the projects at the organization and department levels could help generate development of learning organization at Suwannaphum Technical College and could respond to the factors of being learning organization.
\end{abstract}

Key words: Learning organization, technical college, model, knowledge, foreign countries, Thailand

\section{INTRODUCTION}

Social, economic and technological changes have both competitions and cooperation to seek common benefits. There are not only competitions in terms of financial powers and manpowers but also there are competions in quality and indigenous knowledge as Marquardt (1994) says that important pushing force to change the business world and to generate the whole organization learning is an inevitable thing.

That is, creative job change using teamwork is for organization to survive. Owen also points out that in the part the important duties of business organizations were to make products and profits. At present however, what should be given the importance to is being efficient learning organization. All this does not mean that products and profits are not import. Without learning rapidly efficiently and continuously, the business will not have any more products and profits. That is to say, each organization must adjust itself for existence from external push and changes from the changing stream. This is in accordance with Geoffrey (1986) who states that if expecting further survival either the researchers are individuals or organizations or the country, the researchers must create learning culture and every organization must change itself to learning organization. Thailand aims to develop itself to a quality society and indigenous knowledge society. Indigenous knowledge

Corresponding Author: Chuthaphon Bunwan, Graduate School, Mahasarakham University, Kantarawichai District, 44150 Mahasarakham, Thailand 
and learning society aims to provide opportunities for all Thai people to be able to think and to do, to be reasonable, initiative and creative, to be able to have lifelong learning and to be quick-witted. All these aim to be ready to accept changes and such technological advancements as utilization of technology for faciliting and rapidity in study use. In addition, states about learning in National Education Standards, Standard 3 that guidelines for creating the learning society or knowledge society, creating the learning way and learning resources to be strengthened, learning, knowledge, innovations, media and technology are important factors of development learning to knowledge society (Office of the Secretary Educational Council, 2005).

Also, the royal decree on rules and methods of good country affairs governance 2003, Article 11 of Section 3 says: the state/sector has its duty to develop knowledge to be a type of learning organization in regularity. The organization must perceive information and can compile knowledge in different aspects for accurate applications in official practice. Therefore, the status needed by the organization is creation of sustainability for the organization.

One management instrument helping the organization be sustainably successful is learning organization. This will generate knowledge transference among one another in parallel with receiving external information. It is facilitation to provide opportunities for finding out guidelines for best practices. Moreover, Pedler and Berkon (1991) studied outcomes of implementing a guideline for learning organization in practice. Learning organization consists of learning strategies, participation in policy management, information systems, accounting and controlling and audition, internal exchange, rewarding, personnel motivation project, interorganization learning and learning climate.

From an analysis of organizational contexts to find out strategies for developing government officials and vocational education personnel that were external and internal factors by analyzing strengths and weaknesses, opportunities and obstacles to find out strategies for developing government officials and vocational education personnel, it was found that there were the following weaknesses: management of database of personnel development is unsystematic and unupdated. Creation of network of cooperation with different agencies in the state and private sectors for developing different aspects in limited, not various and not coverage (Office of the Vocational Education Commission, 2005).

Knowledge management in education institution offices is unsystematic. Channels to access the body of knowledge of vocational education and management are limited and not thorough. Measurement and evaluation of job performance do not yet refer to personnel's degree of competency according to the strategies. From what have been mentioned earlier, it can reflect management within the educational institution organizations which is not on the basis of actual being learning organization.

It generates not so efficient practice as it should be. It affects professional effectiveness and excellence of school and college students who attend learning. Therefore, the researcher is interested in conducting a study of learning organization at a technical college by developing a model of learning organization at that technical college for utilization in developing the college leading to learning organization in the future. To develop a model of learning organization at technical college. To examine outcomes of trying out the model of learning organization at Suwannaphum Technical College.

\section{MATERIALS AND METHODS}

The mixed method research was employed using survey research and development research.

Sample: The sample used consisted of: the sample to obtain the model of learning organization consisted of 25 experts, obtained using the purposive sampling technique. They were divided into 4 groups: a group of 10 highest-ranking educational institution administrators at technical colleges which used to receive outstanding educational institution administration awards or used to receive administration royal awards; a group of 5 ex-qualified persons or experts in advising students in the topics involving learning organization or persons with experiences in conducting research at the doctoral degree level in the topics concerning learning organizations; a group of 4 people with academic works appearing to the public comprising textbook writing or accepted articles writing about learning organization and a group of 4 persons with experiences in learning organization administration in the successful private sectors or persons with knowledge and experiences in administration of the Office of the Vocational Education Commission (2005). The sample of 45 persons to examine outcomes of the model of learning organization which the researcher used to try out at Suwannaphum Technical College using the purposive sampling technique comprising 4 administrative line personnel and 41 teachers.

Instruments for data collection: The instrument used for checking the model of learning organization the technical colleges was a 5-rating-seale questionnaire. The instruments used for examining outcomes of the model of learning organization at the technical colleges were a note 
taking form on outcomes of an academic seminar and a note-taking form on data from brainstorming and an evaluation form on coverage of learning organization plans an evaluation form on teacher's teaching and an evaluation form on the project for developing learning organization plans.

Procedure: The study was conducted in 2 stages with the following details:

Stage 1: Developing the model of learning organization at the technical Colleges. Studying documents, concepts, theories, principles and related literature concerning learning organization both in Thailand and in foreign countries, examining operation at the technical colleges, compiling and synthesizing the essences obtained form the studies in order to obtain a draft of the model of learning organization at the technical college; constructing a 5-rating-scale questionnaire for checking the model by a thesis advice committee and qualified persons for them to make comments and recommendations about the constructed questionnaire; checking the model of learning organization at the technical college by asking 25 experts.

Stage 2: Studying outcomes of trying out the model of learning organization at Suwannaphum Technical College, Amphoe Suwannaphum, Changwat Roi Et. Operation to generate learning organization at the organizational level by holding an academic seminar entitled. The Development of Learning Organization at Suwannaphum Technical College. In the seminar program there were: knowledge provision by the researcher concerning learning organization having the personnel from each department have brainstorming within its own department group to construct learning organization to generate for the college, presenting at least 1 project in each department.

After that one or more representatives of each department presented the projects to the forum. Data were collected and outcomes were summarized by using a notetaking form on the operational outcomes. Operation to generate learning organization at the department level by presenting the project entitled.

The Development of Learning Organization Plans at the General Education-Related Department. Programs were determined including Brain-storming of the teachers in each department by each teacher bringing in his/her own old plan as performed making comments on his/her own plan together with presenting problems found from practice having every teacher write his/her own plan for $5 \mathrm{~min}$, sharing plans among them for making comments on each plan and presenting their opinions about planmaking together each teacher taking notes of his/her own as received from plan presentation, summarizing the outcomes from comments on each plan by having a responsible person make conclusions and presenting their opinions about the model of writing learning organization plans of the college; collecting data by taking notes on the note-taking form on the outcomes of brainstorming.

Inviting 1 expert in making plans for organization of learning who was the academic affairs administrator to provide knowledge of plan-making. Operation of writing plans together. The plans were really used for teaching and data were collected, respectively including collection data form brainstorming teachers in the general educationrelated department by taking notes on outcomes of brainstorming, collecting data from evaluation of coverage of plans for organization of learning from the expert who gave knowledge, collecting data from teacher's teaching as rated by learners and collecting data from project evaluation as rated by teacher participants using a 5-rating-scale questionnaire.

Data analysis: The researcher analyzed the following collected data:

- Analysis of data collected using a 5-rating-scale questionnaire on factors of learning organization at the technical college, applying a computer program

- Analysis of data collected using an evaluation form on coverage of the plans for organization of learning an evaluation form on teacher's teaching and an evaluation form on the project for developing organization of learning, analyzing data collected using a 5-rating-scale questionnaire, applying a computer program

Statistics for data analysis: The statistics used for analyzing the collected data were mean ( $\boldsymbol{x})$ and Standard Deviation (SD).

\section{RESULTS}

The results of this study of developing the model of learning organization at the technical college were as follows: the model of learning organization at the technical college consisted of the following 11 factors and 52 items. Structure factors comprised reduction of working stages by organizing matrix organization structure. There were limited classes of commands. When jobs or men had changed, job performance could be adjusted according to each situation. Empowerment to the leader of each section within the organization could be made by having participation in expressing opinions. This could help the administrator use the information as an instrument for decision-making. Factors in terms of vision and mission comprised creation of organizational vision as generated 
from brainstorming together with the staff of personnel inside and outside the organization to generate clear goals. The vision and mission at the section, department and person levels should be created to generate congruence with one another in job performance leading to the goals. Determination of vision and mission should be in accordance with the model and indicators of organizational success.

Factors in terms of context and culture comprised arrangements of physical and mental contexts to help in learning of personnel, learners or service users. External and internal contexts were analyzed to be in congruence with the direction of growth and changes with an emphasis on outcome-oriented job culture by upholding the principle of job performance evaluation using concrete indicators.

Factors in terms of instructional leadership comprised being a good example in morality and ethics, administration by upholding the principle of democracy and the principle of good country affairs and social governance. Academic affairs plans were determined from the top level (organization) to the bottom level (department) and action following the established plans by the instructional leader providing directing, supervision and follow-ups in regularity and the leader dared to change study-style by using the research process for problem-solving and job development to produce manpower to respond to the workforce market and living-making by doing independent careers.

Factors in terms of communication comprised regarding organizational image and reliability before transferring message. Emphasis was on twocommunication and feedback. Emphasis was also on communication through technology to be able to extend the boundary of sending out information spaciously. This could help more management. Factors in terms of management and transference comprised knowledge management under the stage of systematic model, aimed to develop and adjust core competency to respond to service users' expectations, considered knowledge storage in categories in priority by having technology systems help storage.

Factors in terms of technology and information comprised utilization for learning, regarding types of work use, organizing the work process of systematic information which consisted of input, process and output by using technology to help create network of technology and information to cover all of the people involved by linking the information to external organizations. These included entrepreneurial please, communities and parents. Factors in terms of team learning comprised action learning by using current conditions as learning resources and authentic problem-solving; development of learning skills consisting of systematic thinking, development of thinking models, directed learning and discussion, developing the working-team leading to potential excellence of each team. Factors in terms of stimulation and motivation comprised assigning work to the personnel, regarding knowledge and ability, enhancing learning and rotating work to encourage to generate the flow of knowledge throughout the organization, creating work attitude for everyone to have positively creative thinking about work performance.

Factors in terms of personnel development include planning for personnel development to be in congruence with standards of the Office of the Vocational Education Commission. In each fiscal year, the personnel must be individually developed no $<20 \mathrm{~h}$. Methods of personnel evaluation are selected to use to be in congruence with the purposes of evaluation in each aspect. And factors in terms of evaluation include evaluation using indicators in 4 perspectives according to the principle of Balanced Scorecard (BSC), making self-study report at the person level and job level and making self-assessment report at the organization level to be in congruence with one another and dissemination of the part involved for organization evaluation to be a part of regular work using the quality administration cycle comprising PDCA (plan, do, check and act).

For the study of outcomes of trying out the model of learning organization at Suwannaphum Technical College by organizing the seminar project entitled Developing Learning Organization at Suwannaphum Technical College, it was found that totally 15 projects were obtained to implement in developing the college.

They were learning sharing corner project, project for developing writing knowledge management plan, project for improving the learning-teaching area, project for developing classroom climate and project for installing fans for ventilation, project for developing information technology, project for clump garden of electricity department, project for developing team learning of department teachers, project for developing instructional media within the department, project for providing IT equipment, project for improving record and registration program, project for enhancing integrated teaching skills, project for sport field against drugs, project for college's database, project for developing organizational learning sharing center and project for developing cooperation with the community for organizing projects at the department level entitled Developing Plans for organization of learning of the general education-relations department.

It was also found that from brainstorming of the general education-relations department teachers most of them had knowledge and understanding of plan writing. However, there were details of some contents which they had to study and make understanding for supplement to 
plan writing. Convenience in plan writing was that there were models to be used as the same guideline of the college. For the results of analyzing data about evaluation of coverage of the learning organization plan, it was found that there were means ranging 5.00-3.12. This shows that the questionnaire respondents had opinions about coverage of learning organization plans at a medium level of appropriateness to the highest level.

There were different distributions of the data. For the results of analyzing data about teachers' teaching evaluation, it was found that the means ranged 4.00-4.75, showing that learners had opinions about teachers' teaching at a high level of appropriateness to the highest level. There were different distributions of data. And for the results of evaluating projects, it was found that the means ranged 3.33-5.00, showing that the questionnaire respondents had opinions about the projects at a medium level of appropriateness to the highest level with different distributions of data.

\section{DISCUSSION}

Form the results of examining for developing the model of learning organization at the technical college and implementing the model of learning organization at Suwannaphum Technical College, the following issues should be discussed.

The model of learning organization at the technical college consists of structure which is in accordance with the concept of Marquardt (1994) who say that on appropriate structure does not have too many levels of command but it is flexible, fluent and helpful to formation of working-team; it can provide opportunities for the personnel to have decision-making freedom. This is in congruence with Yodpaiboon (2004) who summarize the learning organization characteristics that an appropriate structure should be flexible and fluent with job descriptions, vision and missions.

This finding is in accordance with the principle of the Department of Curriculum and Instruction which states that the method of developing organizational vision must be correctly systematic and have stages (DCI, 2002). Importantly, there must be cooperation from all organizational personnel. A working-staff must be appointed consisting of staff members who have authority to make decision on command and there must be opinions from all organizational stake-holders to coordinate in benefits for all sections.

The finding is also in accordance with the concept of Chamonman who stresses that the model with input, process, output and outcome is the one which is most popularly used for checking educational, environmental. Also, it is in congruence with the concept of Chuito (2002) who states that environmental management for human resource development is the system of environmental management both physically and mentally and instructional leadership. This is also in congruence with the concept of Sararattana (2005) who conducted a study of making school have characteristics of learning organization.

He says that the use of leadership relying on power of informants and experts is more than authority to command by position to communicate. It is in accordance with the principle of who says about determination of efficient strategy for communication that there should be consideration of clear decision on the purposes or causes of real needs for communication, consideration of available resources and determination of organizational reliable image.

Concerning knowledge management and transference, Stewart (1997) says that the organization cannot manage knowledge in its own organization if it cannot define the term knowledge and cannot identify which knowledge is necessary to the organization because different types of knowledge do not have equal values. For all this, the higher rank the knowledge is in the more meaningful and more valuable the knowledge is.

This is in accordance with the concept of Garvin (1993) who state about the research in developing new products generated from the knowledge obtained from failure that it often becomes a tool of success in the future. The findings are in congruence with the principle of Pedler and Berkon (1991) who studied the learning project to examine outcomes of implementing learning organization in practice. They say that information system is one characteristic of learning organization with is the creation of the information system or computer system sued for compiling the outcomes and team learning.

This is also in congruence with the principle of Senge (1990) who states that systematic transference of excellence to generate acceptance of one another must have these techniques: discussion for sharing ideas together discussion by having preparation of teamwork administrative information with the team leader who operates to generate learning, stimulation and motivation.

In creation of work performers' good morale, the superior is the person with the most important part. This is in congruence with the concept of Longworth and Davles who state about characteristics of learning organization that the learning organization should respond to the needs of the environment and society and should stimulate the personnel to work toward the same direction.

The personnel development is in accordance with Standard 2 of the Office of the Vocational Education Commission: the development of curricula and learningteaching organization, indicator $16 \%$ of the personnel within the educational institution must receive 
development according to their responsible functions for no $<20 \mathrm{~h} /$ person/year and the evaluation is in accordance with the concept of Decharin (2003) who says about balanced scorecard that it is the system of administration and evaluation throughout the organization, it is not only the system of evaluation but also determination of vision and strategic plans, then it interprets into all points of the organization to be used as a guideline for operation of all sections and in each person.

The system will provide guideline for solving problems and improving the operation. This is in accordance with the principle of National Education Act 1999 which prescribes education standards and quality assurance in Article 48 of Section 6 that the attached agency and educational institutions must provide the internal quality assurance and must regard that internal quality assurance is a part of the educational administration process which must be continuously operated. Annual reports must be made to submit to the attached agency and agencies involved and the reports must be disseminated to the public to lead to the development of education standards and quality and to underlie external quality assurance which will be in congruence with the principle of the Office of the Vocational Education Commission.

For the study of outcomes of implementing the model of learning organization at Suwannaphum Technical College by organizing the project for seminar to share learning at the organization level and organizing the projects at the department level through the projects, the development of learning organization at the educational institution level has been generated which is in congruence with the factors of learning organization. They are: occurrences of learning teaching supervision and follow-ups, occurrence of academic affairs administration and management by presenting problems upwards. It is in accordance with the concept of Phucharoen (2004) who states that the administrator is the designer of methods of learning.

$\mathrm{He} / \mathrm{she}$ must understand behaviors of learners and teachers. Learning must be in congruence with organizational strategies and core competency. Thinking is adjusted and the knowledge is adjusted for use in how to work. There is creation of good image of general education department to Suwannaphum Technical College. There is two-way communication between the administrative section and teacher personnel. Also, there are formal and informal communications. This is in accordance with the concept of Ma-kasira-Nean (2005) who says about communication that a meeting according to agenda in the working-team is the group meeting for everyone to know of the current work conditions. They must decide how the work will be. Most of the work must be systematically related to one another. It is unnecessary for all types of communication to be formal in reportmaking or meetings because informal meeting can help create a climate of wanting to talk more. Knowledge management occurs under systematic stages including project proposal, project operation and project operation outcome summarization, transference of knowledge between organizational level personnel and the department level occurs. It is in accordance with the principle of Marquardt (1994) who says that the systematic model of knowledge management, subsystems of knowledge which cover knowledge transactions from different learning resources to knowledge use consist of knowledge seeking by collecting information from different sources both internal and external organization, knowledge creation from intending to build innovations up to conducting research. In data storage, the organization must diagnose and classify data and must consider how to treat data. This generates action learning using current conditions as learning resources and authentic problem-solving. It generates development of learning skills and generates development of workingteam leading to excellence according to the team potential.

This is in accordance with the concept of Peters and Waterman (1987) who conducted a study of management of highly successful American companies. They discovered organizational culture which could help the organization reach excellence. These include: emphasis on action, emphasis on closeness to customers, emphasis on freedom to work and feelings of business owners, creating attitude toward working by having everyone have positive opinions about the image of organizational management. This will help everyone have creative thinking in work performance, creating motivation and maintenance of personnel's morale by expressing participation at subteam level.

This is in congruence with Bennett and O'Brien (1997) who present factors of learning organization. They say that parts of these factors are: rewarding and acceptance, creating inspiration to lead the personnel to achieve organizational vision which will originate systematic development of the personnel relying on the step-by-step research process. It is the project which teacher personnel in other departments can adjust and implement for developing plan writing in their own major subjects. It is in accordance with the principle of the DCI (2002) which prescribes that agencies which provide vocational education must use the quality administration cycle as a guideline for action in education provision to be in congruence with vocational education standards for producing and developing people to go into the workforce market, for increasing competition potentials from the national level to international level and it will underlie operation of quality assurance and to be ready for receiving external quality assessment from the Office 
of National Education Standard Assurance and Quality Assessment. It is also in accordance with the principle of National Education Act 1999 which says about internal quality assurance that it is an assessment and follow-up for checking education quality and standards of each educational institution from internal persons by personnel of the educational institution or by the attached agency whose duty is to direct and mentor that educational institution. Checking operational quality is to develop, improve and assess the quality.

\section{RECOMMENDATIONS}

Recommendations for implementing the research findings include:

- In implementing the learning organization model at the technical college, individual educational institutions should be regarded by analyzing problems according to factors of the model for developing educational institutions to meet conditions of current problems

- Educational supervisors or those involving in education provision of the Office of the Vocational Education Commission can implement the learning organization model at the technical college in applying to determination of the policy for administering educational institutions under attachment

- Administrators of educational institutions under the Office of the Vocational Education Commission can implement the learning organization model in application to creation of learning organization to generate within the educational institution

\section{Further research studies:}

- Operational methods or indicators of each factor of the learning organization model should be concretely studied

- Factors or limitations affecting the learning organization model should be studied

- Outcomes of using the learning organization model between/among educational institutions under the same attachment should be comparatively studied

\section{REFERENCES}

Bennett, J. and M. O'Brien, 1997. The Bulding Bolcks of the Learning Orgnization. McGraw-Hill, New York, pp: 77-79.
Chuito, S., 2002. Modern Organizations. Sukhothai Thammathirat Open Universtiy, Bangkok, pp: $207-210$.

DCI, 2002. Explanations in Supplement to National Education Act and Revision. Ver. 2. Religious Affairs Printing House, Bangkok, pp: 1-2.

Decharin, P., 2003. Balanced Scorecard to Practice Guideline. Chulalongkorn University Printing House, Bangkok, pp: 20.

Garvin, D.A., 1993. Building a Learning Organization. Harvard Business, Bangkok, pp: 48.

Geoffrey, H., 1986. Excellence in Industry: Developing Managers-a New Approach. Harper and Row, London, pp: 57.

Ma-Kasira-Nean, W., 2005. Developing Learning Organization. Expernet, Co. Ltd., Bangkok, pp: 115-123.

Marquardt, M.J., 1994. The Global Learning Organization. Irwin Professional Publishing, UK., pp: 18-19.

Office of the Secretary Educational Council, 2005. National Education Standards. Sahai Block and Publishing Partnerships Ltd., Bangkok, pp: 3-8.

Office of the Vocational Education Commission, 2005. A Research Report on the Path of Vocational Education and Technology. Phapphim Publishing, Bangkok, pp: 14-15.

Pedler, M. and J. Berkon, 1991. The Learning Company: A Strategy for Sustainable Development. McGraw-Hill, New York, pp: 41.

Peters, T.J. and R.H. Waterman, 1987. Search of Excellence. Harper and Row, New York, pp: 30-48.

Phucharoen, W., 2004. Learning and Knowledge Management Organization. 3rd Edn., Arayachon Co. Ltd., Bangkok, pp: 236-238.

Sararattana, W., 2005. Administering Factors and Learning Organization. Sapwisut Publishing, Bangkok, pp: 52.

Senge, P.M., 1990. The Fifth Discipline: The Art and Practice of the Learning Organization. Doubleday Currency, New York, pp: 45.

Stewart, T., 1997. Intellectual Capital: The New Wealth of Organization. Crown Business, UK., pp: 75.

Yodpaiboon, K., 2004. Developing tambon administrative organizations leading to learning organization and effectiveness. A Research Report on Research Sponsorships by the National Research Council, Fiscal Years 2004-2005. 